\title{
Duplicate publication and plagiarism: is RHC safe?
}

Silvia Maina ${ }^{1}$, Mario Di Napoli ${ }^{2}$

Editor, SEEd Medical Publishers

UOC Neurologia. Ospedale Generale Provinciale San Camillo de' Lellis, Rieti. Editor in Chief, Reviews in Health Care

Plagiarism is defined as «the practice of taking someone else's work or ideas and passing them off as one's own» (Oxford Dictionary). In publishing, it consists in using others' published and unpublished ideas or words without permission or attribution, and presenting them as new and original.

The term "plagiarism" seems something more related to music or literature than to academia. In 1973 The Beatles were sued for plagiarizing Chuck Berry's "You Can't Catch Me" in their hit "Come Together". Dan Brown, author of "The Da Vinci Code", was accused by novelist Lewis Perdue for plagiarizing his novels "The Da Vinci Legacy" and "Daughter of God".

Anyway, famous cases of plagiarism are also present in medical publishing, and are related to every kind of published or unpublished manuscripts, print or electronic, books and journal articles, abstracts and research grant applications. Article retractions because of plagiarism are not rare: just to give an example, a manuscript [1] was retracted from the April 2010 issue of Anaesthesia and Analgesia when it was found to have been plagiarized from five other published manuscripts. In the retraction note, the Editor in chief of the journal, Steven L. Shafer, after apologizing to authors whose text was plagiarized, to readers, and to the affected journals for the violation of copyright, adds that many journals «are increasingly employing sophisticated software to detect plagiarism. [...] Authors should be aware that most journals routinely employ plagiarism detection software, and that any plagiarism is likely to be detected» [2].

While plagiarism represents obviously scientific misconduct, a different form of "copy and paste" is more controversy. It's the so-called "self-plagiarism", or duplicate publication (also, redundant, dual, repetitive, fragmented, salami, and disaggregated publication [3]). The International Committee of Medical Journal Editors (ICMJE) defines duplicate publication as one whose contents substantially overlap with a previous publication with at least one common author. 
It is very common in biomedical literature: in their "Why and how do journals retract articles?", Wager and Williams analyzed Medline retractions between 1988 and 2008, finding out that 17\% occurred due to redundant publication [4].

It can be seen in several forms [5-7], such as:

- Same study sample, control data, or study outcomes. In the case of duplication of a clinical trial, duplicate publications can also affect the reliability of meta-analyses, as the same dataset might be counted more than once.

- The so called "salami slicing": instead of publishing a large study as a single article, sometimes authors "slice" it into several smaller articles.

- Multiple submission, within a few weeks' gap, of the same article to two or more different journals, ending in publication in both the journals.

- Republication in another language (an article that has originally been published in a non-English journal and the author wishes to publish a translation in an English journal for wider circulation or he wants to republish an article from an English journal in a local language).

Is duplicate publication scientific misconduct? The answer is controversial.

For some authors, duplicate publication constitutes a scientific misconduct, because it's seldom accidental, rather mostly deliberate $[8,9]$.

Others, on the contrary, accept that it can be "unintentional". Many authors are not aware of copyright rules, nor of publication ethics. For example, duplicated publication can result as a consequence of cosubmission of the same article to two or more journals. In this case slowness of editorial processing can be the excuse for this behaviour. Another very common case is the publication of the same article in two different languages, with the aim of disseminating scientific information to a larger number of readers. Even if this behaviour can not be considered unethical, authors should be aware that a copyright infringement can be involved, and therefore check with their publishing house.

Reviews in Health Care is not free from this problem. RHC processes submitted manuscripts on the understanding that they are submitted exclusively to only one journal. As stated in our Guidelines for Authors, $R H C$ doesn't consider manuscripts that are being simultaneously submitted to other journals (this to avoid copyright problems, i.e., two journals claiming the right to publish the same manuscript, and to implement a cost-effective use of resources, avoiding to unnecessarily undertake the work of peer review, editing, processing and publishing the same manuscript).

Some cases are not considered duplicate submission:

- a manuscript that has already been rejected by another journal;

- a complete report that follows publication of a preliminary report (e.g., an abstract or poster that has been presented at a professional meeting), provided it has not been published in full nor is being considered for publication in full in the meeting proceedings. In this case we always advise authors, to avoid risks, to make full disclosure to the journal editor at the time of submission;

- pre-print servers including authors' personal and institutional websites;

- open science, i.e., data posted on wikis, blogs, electronic online notebooks, networking websites (citing the source);

- deliberate secondary publication: for example in the case of guidelines produced by government bodies or professional organisations. Specific conditions should be met for secondary publications: the most important is obtaining agreement of all the authors and approval from the editors of both journals.

In scientific journals, the reader expects to read original articles and any kind of self-plagiarism violates such expectations of the reader. Anyway, in reviews publication, as it's the case of Reviews in Health Care, the author may borrow significantly from his/her own previous work. For example, suppose an author has been writing a review on the pathophysiology of insulin secretion. Of course he can not change the mechanism of regulation of insulin secretion in pancreatic islets in order to avoid self-pla- 
giarism. In these cases, the best option is that the review gives some additional contribution to what is already know on this subject. In any case, where there is the potential for overlap or duplication, we require that authors are transparent, informing the journal editor and citing the original article properly. Editors and reviewers have certainly an essential role in detecting matters related to scientific misconduct and avoiding plagiarism and duplicate publication. If today, with the advancement of technology, plagiarism is easier because information is easily available online, it is also true that Internet can help editors and reviewers in detecting copied material. Anyway, we don't believe that this "you will be caught" method is the best way to manage the problem. The responsibility to maintain the integrity of the literature rests with editors, reviewers, authors, as well as the readers. Cooperation between authors and editors, and transparency are the best tools to reach the common goal, which is the advancement of the knowledge of the discipline as a whole.

\section{References}

1. Memis D, Inal MT, Temizoz O, et al. The effect of celiac plexus block in critically ill patients intolerant of enteral nutrition: a randomized, placebo-controlled study. Anesth Analg 2010; 110: 1071-5

2. Shafer SL. You will be caught. Anesth Analg 2011; 112: 491-3; http://dx.doi.org/10.1213/ ANE.0b013e3182095c73

3. Dogra S, Yadav S. Duplicate publication: what an editor can do? IJDVL 2010; 76: 99-102; http:// dx.doi.org/10.4103/0378-6323.60537

4. Wager E, Williams P. Why and how do journals retract articles? An analysis of Medline retractions 1988-2008. J Med Ethics 2011; 37: 567-70; http://dx.doi.org/10.1136/jme.2010.040964

5. Cicutto L. Plagiarism: avoiding the peril in scientific writing. Chest 2008; 133: 579-81; http:// dx.doi.org/10.1378/chest.07-2326

6. Johnson C. Repetitive, duplicate, and redundant publications: a review for authors and readers. $J$ Manipulative Physiol Ther 2006; 29: 505-9; http://dx.doi.org/10.1016/j.jmpt.2006.07.001

7. Das N, Panjabi M. Plagiarism: why is it such a big issue for medical writers? Perspect Clin Res 2011; 2: 67-71; http://dx.doi.org/10.4103/2229-3485.80370

8. DeAngelis CD. Duplicate publication, multiple problems. JAMA 2004; 292: 1745-6; http://dx.doi. org/10.1001/jama.292.14.1745

9. Abraham P. Duplicate and salami publications. J Postgrad Med 2000; 46: 67-9 